\title{
DIURNAL VARIATION OF METABOLITES IN PLASMA AND MILK IN EARLY LACTATING DAIRY COWS
}

\author{
Nicolaj Nielsen, Klaus Lønne Ingvartsen, Torben Larsen and Mie Kjorgaard.
}

Department of Animal Health and Welfare, Danish Institute of Agricultural SciencesResearch Centre Foulum, P. O. Box 50, DK-8830 Tjele, Denmark.

\section{Introduction}

Future health and performance management systems should focus on early identification and subsequent prevention of physiological imbalances and production diseases as e.g. subclinical ketosis in dairy cows. Consequently, there is a need for biological indicators that reflectings the status of the dairy cow. ß-hydroxybutyrate (BOHB) in milk is a potential indicator of subclinical and clinical ketosis in dairy cows (1). The concentration of BOHB in plasma is influenced by feedstuffs (2), feeding times (3) and feeding frequency (4), and it is therefore likely that the usefullness of BOHB in milk as an indicator is compromised by these factors. The objectives of the present study were to investigate the diurnal variation and to quantify the effect of a ketogenic ration and the feeding frequency on the concentration of BOHB in milk and BOHB, glucose and non-esterified fatty acids (NEFA) in plasma.

\section{Materials and methods}

Eight multiparous cows in early lactation were included in a cross-over design with two 14 -days periods. Four cows were fed either a ketogenic or a standard TMR ad libitum in period I (initiated 25 \pm 6.8 DIM). In period II (initiated $39 \pm 6.8 \mathrm{DIM}$ ) cows were changed to the other TMR. The ketogenic ration was fed at 10 a.m. and 4 p.m., while the standard ration was fed at 10 a.m., 4 p.m., 10 p.m. and 4 a.m. The Ccows were housed in tie stalls and milked twice a day at approximately $4 . .45$ a.m.a.m. and $4 . .15$ p.m.p.m. Blood and milk samples were collected hourly for 24 hours on day 10 in each period. Plasma samples were analysed for BOHB, NEFA and glucose, and milk was analysed for BOHB.

\section{Results and discussion}

The highest level of NEFA in plasma was seen during the morning, before the feeding at $10 \mathrm{a} . \mathrm{m}$. This was especially the case for cows fed the ketogenic TMR ration, and was most likely caused by a low feed intake of this diet during the night. Glucose in plasma was not significantly influenced by type of TMR diet, and did not show any diurnal variation. The diurnal variation of BOHB in milk was not significantly influenced by feed ration and was not related to times of feeding. However, the diurnal changes of BOHB in milk were related to the time of milking, with the highest concentrations between milkings and the lowest concentrations around the time of milking. BOHB in plasma was increased for the ketogenic ration compared withto the standard ration, but only during the evening. The diurnal changes of BOHB in plasma did not appear to be related to times of feeding. This is in contrast withto earlier experiments where concentrates werehave been fed twice daily $(3,5)$.

\section{Conclusion}

The diurnal variation of BOHB in milk does probably not hamper the use of BOHB in milk as an in- 
dicator of subclinical ketosis in dairy cows. Feeding a TMR ad libitum seems to reduce the diurnal variation of $\mathrm{BOHB}$ and glucose in plasma reported in earlier studies where concentrates were fed twice daily.

\title{
References
}

1. Enjalbert, F. et al. 2001. J. Dairy Sci. 84, 583-589. (2): Murphy, J. J. 1999. Anim. Feed Sci. Tech. 78, 189198. (3): Andersson, L. and Lundström K. 1984. Zbl. Vet. Med. A. 31, 340-349. (4): Eicher, R. et al. 1999. Am. J. Vet. Res. 60, 1493-1499. (5): Blum, J. W. et al. 1985. Zbl. Vet. Med. A. 32, 401-418.

\section{A REVIEW OF THE EFFECTS OF FEEDING NIACIN TO EARLY LACTATING DAIRY COWS}

\author{
Nicolaj Nielsen and Klaus Lønne Ingvartsen \\ Department of Animal Health and Welfare, Danish Institute of Agricultural Sciences Research Centre Foulum, \\ P. O. Box 50, DK-8830 Tjele, Denmark.
}

\section{Introduction}

The use of niacin for Danish dairy cows has recently received increased interest in the dairy industry. This interest is based on an expectation that niacin will increase milk yield and/or prevent ketosis. In ruminants, niacin (vitamin B3) is synthesised by the microflora in the rumen. It has been questioned whether the synthesis of niacin in the rumen is adequate in order to secure an optimal production and health in dairy cows in early lactation. The objective of this report wasis to review the effects of niacin on the fermentation pattern in the rumen, blood and liver parameters, feed intake and performance to determine if niacin is able to improve the negative energy balance and prevent ketosis in early lactating dairy cows.

\section{Results and discussion}

Feeding 6-12 g of niacin/cow/day does not change the fermentation pattern, the total concentration of volatile fatty acids, or the $\mathrm{pH}$ in the rumen. Feeding 6-12 $\mathrm{g}$ of niacin /cow/day in early lactation increases the concentration of niacin in plasma, thus, increasing the supply to the cow. The increased supply of niacin does not significantly affect plasma concentrations of glucose and NEFA (Figure 1), This indicatinges that supplementary niacin does not reduce the mobilisation of adipose tissue, and consequently does not improve the negative energy balance. However, there is a tendency that supplementary niacin decreases the plasma concentration of b-hydroxybutyrate (BHB), thus acting antiketogenically (Figure 1). Supplementary niacin does not affect the content of TAG or lipid in the liver. Feeding 6-12 g of niacin/cow/day does not affect feed intake, milk yield or fat and protein content of the milk (Figure 2). Furthermore, niacin supplementation is not able to prevent the drop in the protein content of the milk, which is typically seen when allocating supplementary fat in a feed ration. Only one study has investigated the effect of niacin supplementation on the incidence of ketosis, and reported a tendency towards a lower incidence when feeding $6 \mathrm{~g}$ of niacin/cow/day. 


\title{
Conclusion
}

Supplementary niacin does not reduce the mobilisation of adipose tissue or the content of lipid in the liver. It is therefore unlikely that niacin can prevent fatty liver and ketosis. Furthermore, niacin does not affect feed intake, milk yield or milk composition in early lactating dairy cows.

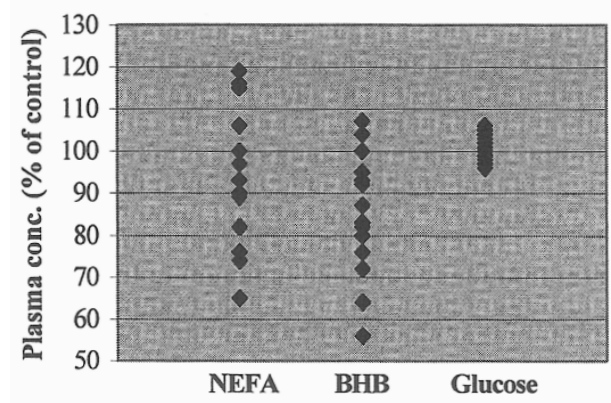

Figure 1. The effect of niacin on plasma concentrations of NEFA, BHB and glucose in early lactating dairy cows shown as percentage of control group (based on 10 references).

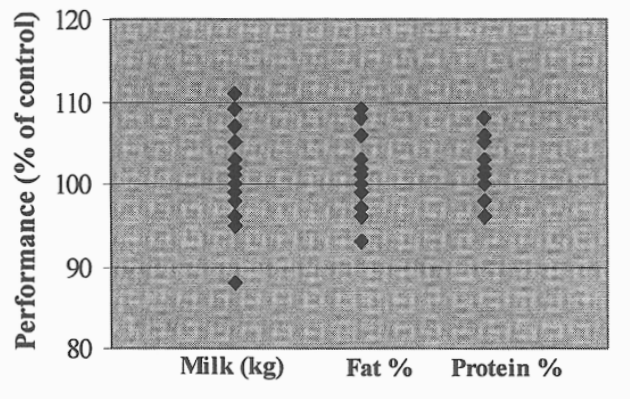

Figure 2. The effect of niacin on milk yield and milk composition in early lactating dairy cows shown as percentage of control group (based on 8 references).

\section{EFFECTS OF GLUCOCORTICOIDS ON IMMUNOLOGICAL PARAMETERS AND ON FAT METABOLISM DURING SHORT TIME TREATMENT}

\author{
M. Fürll, M.N. Dabbagh, B. Fürll, F. Jäckel, L. Jäkel, H. Kirbach, B. Knobloch, M. Krüger, \\ I. Leidel, T. Sattler, K. Schäfer, U. Schwarzer, Th. Witteck \\ Department of Internal Medicine, Veterinary Faculty Leipzig; E-mail: mfuerll@rz.uni-leipzig.de
}

\begin{abstract}
Introduction: Among the veterinary surgeons, uncertainty over the therapeutic use of Glucocorticoids prevails because of the possible immune suppression as well as the stimulation of lipolysis. Partially, veterinarians do not differentiate between the application over a short or long time and the dosage given, hence they rather avoid using this GCS preparations. Thus the pharmacological effects of glucocorticoids, their potential that cannot be replaced by other drugs, remain unused. Glucocorticoids are, for example, needed to cure septic shocks or reperfusion disorders.
\end{abstract}

Objective: In two complexes investigations were performed to answers to the following 3 questions: 1) Has only one application of GCS an effect on the performance of the phagocytosis, on the concentrations of endotoxins and on the anti-lipid-A-AB-titer? 2) Do GCS applied once or repeatedly stimulate the lipolysis as well as the liver fat content? 3) How are other metabolic parameters, the morbidity as well as the performance influenced?

Experimental design: Complex I: The influence of immunological para-meters was checked on 25 cows from two farms by means of Dexamethason. Complex II: The influence of Dexamethason or Prednisolon was tested in cows and sheep respectively: in basal metabolism, fasten stimulated -, 
Epinephrine stimulated -, lactation stimulated -, partus stimulated as well as operation stimulated lipolysis.

Results: I) Under the influence of GCS, the intensity of phagocytosis (ip) as well as the proportion of phagocytized cells did rise insignificantly in the granulocytes, but significantly in monocytes. In the GCS treated group, the concentrations of endotoxin rose less, the ALA-AB-titers rose more intensively. II) In all cases of stimulated lipolysis (food deprivation resp. energy lack [early lactation], epinephrine application, stress influence [parturition, operation]) we observed increased free fatty acids (FFA) and $\beta-\mathrm{OH}$-butyrate (BHB), reduced insuline concentrations in the blood as well as enhanced liver fat content in the untreated control group. Pretreatment with a glucocorticoid never induced increased FFA and liver fat as signs of a stimulated lipolysis, but enhanced glucose and glycogen as well as reduced or unchanged FFA and BHB concentrations. The following chain reaction was always observable: glucocorticoids $\rightarrow \uparrow$ glucose $\rightarrow \uparrow$ insuline $\rightarrow \downarrow$ FFA $\rightarrow \downarrow$ liver lipids. Also other parameters of liver function (AST, GLDH, Bilirubine, Urea, total Protein) were never changed. The same results we found also in sheep (basal as well as fasten metabolism). In none of the experiments, the cortisol concentrations were depressed longer, but for a short time reduced $\mathrm{T}_{3}$ as well as $\mathrm{T}_{4}$ concentrations were observed. On the first day after parturition Voren ${ }^{\circledR}$ was applied, showing positive results. Compared with the untreated group, the morbidity and the performance were better in the Voren ${ }^{\circledR}$ group. Other results show a positive effect of glucocorticoids on the postpartal acute-phasereaction. The lipolysis and ketogenesis were reduced.

Conclusions: Glucocorticoids do not influence the phagocytic activity when applied for a short period of time. They act indirectly antilipolytic in ruminants CGS act against reperfusion injuries, which does not disturb the wound healing after abomasal reposition. CGS decreases the morbidity in the early lactation and increases the 100 days milk yield.

\title{
EFFECT OF ENERGY CONCENTRATION IN THE FEED AND MILKING FREQUENCY ON LIVER LCFA METABOLISM IN EARLY LACTATING DAIRY COWS
}

\author{
Jens Bech Andersen ${ }^{1}$, Torben Larsen ${ }^{1}$, Mette Olaf Nielsen ${ }^{2}$, Klaus Lønne Ingvartsen ${ }^{1}$ \\ ${ }^{1}$ DIAS, Department of Animal Health and Welfare, Research Centre Foulum, P.O. Box 50, DK-8830 Tjele, \\ Denmark. ${ }^{2}$ Royal Veterinary and Agricultural University, Dept. of Anatomy and Physiology, \\ DK-1870 Frederiksberg C, Denmark
}

\section{Introduction}

Hepatic lipidosis has been a problem for decades and it seems to cause problems for more than $50 \%$ of dairy cows in the periparturient period (1). High milk production and large losses of body condition score in early lactation have been concluded to be risk factors for hepatic lipidosis (1). Two key factors may be assumed important for preventing hepatic lipidosis: 1) avoiding excessive mobilization of LCFA from adipose tissue, 2) a stimulation of the hepatic capacity for LCFA oxidation.

Different energy concentration in feed affects energy intake and mobilization in early lactation. Further, milk yield may be increased at a high level by milking $3 \mathrm{x}$ daily instead of $2 \mathrm{x}$ daily. The purpose of the present study was to test the combined effects of TMR energy concentration and in- 
creased milk yield, obtained by increased milking frequencies, on hepatic LCFA metabolism in early lactation.

\title{
Material and methods
}

Forty multiparous Danish Holstein cows, fed the same TMR during the dry period, were included in a 2x2 factorial design. One factor was feeding a high energy density TMR (H: 75\% concentrate) or a low (L: $25 \%$ concentrate) from calving to eight weeks postpartum. The other factor was milking two (2) or three (3) times daily. The four treatments were designated L2, L3, H2, and H3. Liver biopsies were sampled week $-2,2$, and 7 postpartum, and analyzed for triacylglycerol (TAG), glycogen, and in vitro capacity of palmitate oxidation.

\section{Results and discussion}

There were no differences between any of the analyzed parameters in hepatic tissue prior to calving (week -2). Liver TAG content was lowest for cows fed diet $\mathrm{H}$ compared with cows feed diet L in early lactation ( 10.6 vs. $15.7 \mathrm{mmol} / \mathrm{g}$ tissue, $\mathrm{P}=0.04$ ). Liver glycogen content was not affected by diet or milking frequencies in the present experiment. Cows allocated diet $\mathrm{H}$ had the highest in vitro capacity for oxidation of LCFA in early lactation $(23.5 \mathrm{vs} .17 .7 \mathrm{nmol} / \mathrm{g}$ tissue/ $\mathrm{h}, \mathrm{P}<0.03)$. However, a significant interaction between energy density in the diet and milking frequencies $(\mathrm{P}<0.05)$ showed that particularly cows on treatment L3 had less hepatic activity than cows on treatment $\mathrm{H} 2$ and $\mathrm{H} 3$. The present experiment shows that high compared to low TMR energy density has a positive effect on risk of hepatic lipidosis in early lactation. Further, increased milk yield, due to increasing milking frequencies, increases the risk of hepatic lipidosis, unless the cows are fed a high TMR energy concentration.

(1) Jorritsma, R. et al. Livestock Prod. Sci. 68, (2001), 53-60

\section{INFLUENCE OF NORTHERN GERMAN MOULDS AND ANORGANIC SALTS ON RUMINAL CELLULASE ACTIVITY (IN VITRO)}

\author{
Höltershinken, M., A. Höhling, P. Hoffmann* a. H. Scholz \\ Clinic for Cattle Diseases, School of Veterinary Medicine; Bischofsholer Damm 15, D-30173 Hannover, \\ Germany; *German Collection of Micoorganisms and Cell Cultures, D-Braunschweig
}

Non ruminants lack cellulolytic enzymes. That's why they 're not able to digest cellulose. Cellulases however are wide spread in microorganisms. Living in symbiosis with ruminal microbes like bacteria, protozoa and fungi, ruminants can metabolize cellulose and use it energetically. Cellulose is build up by glucose elements connected $\beta$-glycosically and is metabolized to glucose by exo- and endocellulase and cellobiose. Cellulases can be influenced positively and negatively.

The aim of these experiments was to test the influence of moulded hay on the one hand and that of anorganic salts on the other hand on ruminal cellulolytic activity (CA, in vitro, RUSITEC). The 
moulds used were harvested from pastures in Northern Germany where several cattle of different herds which showed the clinical signs of $\mathrm{CCN}$ and responded well to thiamine application. Since the grass was overgrown with rust and other fungi we tested the influence of those fungi (Alternaria alternata -AA, Epicoccum nigrum -EN, Mucor racemosus -MR, Fusarium graminearum -FG, F. poae -FP, F. culmorum -FC, Cladosporium herbarum - $\mathrm{CH}$ or Ulocladium chartarum -UC) on the one hand and that of anorganic salts $\left(\mathrm{MgO}, \mathrm{Na}_{2} \mathrm{SO}_{4}\right.$ and $\mathrm{Na}_{2} \mathrm{SO}_{3}$ as constituents of fertiliers) on the other hand on the ruminal cellulases.

Five investigation periods lasting about 23 days each were carried out. After a control period of nine days a five day testphase followed. During this time two vessels were charged normally and two with moulded hay (moulded with AA, EN, MR, FG, FP, FC, CH or UC) or with $\mathrm{Na}_{2} \mathrm{SO}_{4}, \mathrm{Na}_{2} \mathrm{SO}_{3}$ or $\mathrm{MgO}$ respectively. In the second testphase (five days) daily $0.3 \mathrm{mg}$ thiamine were added. The last days served for regeneration with normal hay. Before feeding the system, rumen fluid was daily taken for the determination of CA $(1,2)$.

The following effects on the CA could be noted: AA: $+22 \%$, FG: $+18 \%$, FP and FC: $-38 \%$, EN, MR, $\mathrm{UC}, \mathrm{CH}:+/-0 \%$; $\mathrm{MgO}:+25 \%, \mathrm{Na}_{2} \mathrm{SO}_{4}:-37 \%, \mathrm{Na}_{2} \mathrm{SO}_{3}:+/-0 \%$.

This means that AA, FG obviously have their own CA and FP or FC depending reduction of CA is overcome by thiamine. The latter supports the idea that Fusarium toxins destroy or block a thiamine depending key function of the CA. Furthermore $\mathrm{Mg}^{++}$as cellulase stimulator is known while it was surprising that $\mathrm{Na}_{2} \mathrm{SO}_{3}$ had no influence. May be that the increased fermentation (4 h) after supplementation destroyed the inhibitory effects.

1. Krakow, L. (1990): Untersuchungen (RUSITEC-System) zum Einfluß von Magnesi-umoxid auf Fermentationsvorgänge im Panseninhalt des Rindes. Hannover, Tierärztl. Hochsch., Diss.;

2. Wolf, G. A., a. S. J. Wirth (1990): Application of soluble chromo-genic substrates for assays of polysaccharide endo-hydrolase. In: KLEMENT, Z., K. RUDOLPH a. D: C. SANDS (Ed.): Methods in phytobacteriology Ch.III. Akademiai Kiado, Publishing House of Hungarian Academy of Science, Budapest, 409-413

\title{
INFLUENCE OF MOULDED FEED WITH AND WITHOUT THIAMINE SUPPLEMENTATION ON RUMEN PROTOZOA IN CATTLE (IN VITRO)
}

\author{
A. Höhling ${ }^{1}$, M. Höltershinken ${ }^{1}$, P. Hoffmann ${ }^{2}$ and H. Scholz ${ }^{1}$ \\ ${ }^{1}$ Clinic for Cattle Diseases, School of Veterinary Medicine Hannover, Bischofsholer Damm 15, \\ 30173 Hannover, Germany, ${ }^{2}$ German Collection of Microorganisms and Cell Cultures, \\ Mascheroder Weg 1b, 38124 Braunschweig, Germany
}

The rumen protozoa are anaerob and 4 to $500 \mu \mathrm{m}$ large. They live facultative in symbioses with the ruminant and take part in the ruminal metabolism (e. g. increase of food digestibility, stabilisation of the ruminal fermentation and the $\mathrm{pH}$, supply of essential amino acids and unsaturated fatty acids). Consecutively, the rumen protozoa influence animal's health (increased growth during energy-limited diets, lower incidence of scours in calves, anti acidic effect, detoxification of nitrate and zearalenon, lower incidence of copper intoxication on the one hand, but greater incidence of bloat on the other hand). The protozoa population is affected by its environment, e. g. by the $\mathrm{pH}$, carbohydrates, 
lipids, proteins, vitamins, antibiotics, myco- and phytotoxines. Therefore protozoa were sometimes used as bio sensors in bio assays.

In recent studies, the influence of hay, moulded with Alternaria alternata, Epicoccum nigrum, Mucor racemosus or Ulocladium chartarum were investigated using the long term rumen simulation technique (RUSITEC). The moulds used derived from a Northern German pasture, where cows suffered from CCN probably caused by thiamine deficiency. As the moulds were supposed to have a thiaminolytic effect, the efficiency of thiamine substitution to cope these effects on rumen protozoa was tested, too. Four experiments lasting 25 five days each were carried out. After a control phase of nine days two five day test phases followed. During this time two reaction vessels were charged with moulded hay (moulded with Alternaria, Epicoccum, Mucor or Ulocladium) and two with good hay. In the second test phase all vessels were additionally charged with thiamine. Protozoa were counted by the means of a microscope in daily taken samples and differentiated into small, medium-sized and large types $(81-93 \%, 6-18 \%$ or $0-3 \%$, respectively, of the total number of protozoa under usual conditions).

The moulded hays affected medium-sized protozoa to a different extent (Alternaria alternata: - $16 \%$, Epicoccum nigrum: $-27 \%$, Mucor racemosus: $-9 \%$, Ulocladium chartarum: $+2 \%$ ). Thiamine stabilised small protozoa in general and had positive effects on medium-sized protozoa during the influence of Ulocladium chartarum $(+26 \%)$ as well.

Apparently there exists a specific sensitivity of medium-sized protozoa to certain moulds. Thiamine dependent metabolic pathways seem to get reversibly blocked.

So, while feeding moulded hay or grass to cows for financial reasons, it might be useful to add thiamine (e. g. as yeast) to the feed.

\title{
DEFINITION, CONSEQUENCES AND PREDICTION OF AN ELEVATED KETONE BODY STATUS IN HIGH YIELDING DAIRY COWS
}

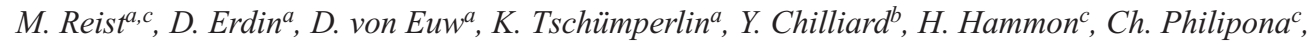 \\ N. Künzi ${ }^{a}$, and J. W. Blum ${ }^{c}$
}
${ }^{a}$ Inst. of Animal Science, Group of Animal Breeding, Swiss Federal Inst. of Technology, CH-8092 Zurich, Switzerland, ${ }^{b}$ Herbivore Research Unit, National Institute for Agricultural Research (INRA), F-63122
St-Genès-Champanelle, France, and ${ }^{\mathrm{c} D i v}$. of Animal Nutrition and Physiology, Inst. of Animal Genetics, Nutrition and Housing, Univ. of Berne, CH-3012 Berne, Switzerland

An elevated ketone body status in dairy cows is associated with detrimental effects on milk production, reproduction and health. However, critical threshold values reported vary widely. Based on that we have determined threshold values for ketone bodies in Holstein cows [ $\mathrm{n}=90$; mean yield 9'500 $\mathrm{kg}$ energy-corrected milk/305 d], held in a research farm. Furthermore, we have studied consequences on productivity traits and disease incidence. In addition, we have investigated whether cows at risk can be detected prior to become ketotic, by monitoring body condition scores (BCS) and different blood and milk traits. BCS and ultrasonic measurements of backfat thickness and fat depth in the pelvic area were evaluated before calving and in wk 1, 4, 8, 12, 16 and 20 postpartum (p.p.). 
Blood samples for determination of glucose, non-esterified fatty acids (NEFA), leptin, insulin, insulin-like growth factor-1 (IGF-1) and ß-hydroxybutyrate (BHBA) were taken 2 wk ante partum and in wk 1-16 and 20 p.p. between 0730 - 0900. Milk samples for the determination of acetone (AC), fat, protein and lactose were taken in wk 1 - 16 and 20 p.p.. Vaginoscopic examination and rectal palpation was done weekly. Threshold values for definition of ketotic status were calculated as mean + 2SD of all values p.p. and as upper $25 \%$ and $10 \%$ limits of maximal p.p. values for each individual cow and resulted in $0.40,0.40$ and $0.87 \mathrm{mmol} / \mathrm{L}$ for $\mathrm{AC}$ and $1.96,2.30$ and $3.51 \mathrm{mmol} / \mathrm{L}$ for BHBA, respectively. Ketone body concentrations above these thresholds did not occur before wk 2 p.p.. Exceeding of these thresholds apart from the upper 10\% limit for BHBA resulted in a decrease in milk yield (- $417 \mathrm{~kg}$ to $-654 \mathrm{~kg} / 305 \mathrm{~d} ; \mathrm{P}<0.05)$. AC concentrations above $0.40 \mathrm{mmol} / \mathrm{L}$ were associated with a 3.24 times higher risk for endometritis $(\mathrm{P}<0.06)$. BCS at calving $\geq 3.50$ and $\mathrm{BCS}$ loss $>0.5$ during the first 8 wk of lactation were better associated with elevated ketones than ultrasonic measurements. Low glucose and high BHBA and AC concentrations in wk 1 p.p. were significant risk factors for a subsequently elevated ketone body status. The other measured metabolic and endocrine traits in blood plasma and milk components were not suitable to predict the development of ketosis. In conclusion, a routine determination of milk $\mathrm{AC}$ in the first wk after calving may help to predict the development of ketosis and to prevent production losses and endometritis, because cows with milk AC concentrations above $0.075 \mathrm{mmol} / \mathrm{L}$ were 5.6 times more likely to exceed the critical threshold later in lactation $(\mathrm{P}<0.01)$. Determination of milk AC concentration very early in lactation can therefore be a tool in the herd-health management of high yielding dairy cows.

\title{
THE RELATIONSHIP BETWEEN PARTURIENT PARESIS AND FAT COW SYNDROME IN DAIRY COWS
}

\author{
Mutlu Sevinc, Veysi Aslan
}

Selçuk University, Faculty of Vet.Med.

This study was conducted to find out the association between parturient parasis and fatty liver. For tis purpose, 20 dairy cows with parturient paresis and 10 healthy were used. Ionized and normalized calcium concentrations in the plasma and blood $\mathrm{pH}, \mathrm{HCO}_{3}, \mathrm{PO}_{2}, \mathrm{BE}$ values and metabolic profile ( $\mathrm{P}$, $\mathrm{Mg}, \mathrm{Na}, \mathrm{K}, \mathrm{ALT}$, fosfolipid, protein, $\mathrm{CPK}$, albumine, cholesterol) in the serum samples were evaluated in order to reach a diagnostic and therapeutic results in dairy cows with parturient paresis. All the cows (were subjected to clinical and laboratory examinations and percutaneous liver biopsy were provided.

The blood $\mathrm{pH}, \mathrm{HCO}_{3}, \mathrm{BE}, \mathrm{ICa}^{++}, \mathrm{TCa}^{++}, \mathrm{P}, \mathrm{Mg}, \mathrm{ALT}$ and fosfolipid concentrations were significantly $(p<0.001)$ lower, and the value of CPK was significantly $(p<0.001)$ elevated in dairy cows with parturient paresis.

The evaluation of biopsy specimens of the both dairy cows with parturient paresis and healthy dairy cows revealed that, 70 percent of cows in dairy cows with parturient paresis had varying degrees of fatty liver while healthy cows no evidence of fatty liver. 